\title{
MANDIBULAR SEXUAL DIMORPHISM ANALYSIS IN CBCT SCANS IN A
SYRIAN SAMPLE
}

\begin{abstract}
Objectives: This study aimed to develop metrical and angular indices to predict the sex of unknown skeletonized human remains in Syria using the mandibular bone.
\end{abstract}

Materials and Methods: The sample consisted of 99 CBCT scans of the Syrian population (43 males, 56 females) aged between 18-25 years. The collected CBCT images were analyzed on two occasions and by two examiners to test the reliability of measurements. Four measurements were analyzed to be used for sexual prediction analysis as following: CoronoidGonion length (the distance between Gonion and the highest lateral point on the Coronoid process), minimum ramus breadth, Gonial angle, and Bigonial width.

Results: All the aforementioned measurements showed significant statistical sex-related differences. The Bigonial width showed the highest difference with $\left(\mathrm{P}<0.01 \_\right.$mean: $95.17 \pm 6.45 \mathrm{~mm}$ for males, $86.84 \pm 4.81 \mathrm{~mm}$ for females), followed by the gonial angle $\left(\mathrm{P}<0.01_{-}\right.$mean: $127.11^{\circ} \pm 7.87^{\circ}$ for males, $131.52^{\circ} \pm 6.08^{\circ}$ for females). Coronoid-gonion length $(\mathrm{P}<0.01$ mean: $58.61 \pm 6.78 \mathrm{~mm}$ for males, $53.97 \pm 5.26 \mathrm{~mm}$ for females) and minimum ramus breadth $\left(\mathrm{P}<0.01 \_\right.$mean: $29.63 \pm 2.90 \mathrm{~mm}$ for males, 27.89 $\pm 2.73 \mathrm{~mm}$ for females). specificity and sensitivity for the four indices derived function were $79 \%$ and $80 \%$ respectively and the diagnostic accuracy was $79.6 \%$.

Conclusions: The present study suggested that the sex of mandible in Syrian population could be assessed using metrical and angular measurements which considered as an additional tool for sex identification.

Key Words: Forensic anthropology, forensic dentistry, mandible, sex characteristics.

\author{
Mecid Gazi Aljaber Abofakher ${ }^{1}$ \\ Amer Owayda ${ }^{2}$ \\ D *Maher Suresi ${ }^{3}$ \\ D Mahmud Abdülhak ${ }^{1}$ \\ Nofal Houssein ${ }^{4}$ \\ iD Ömer Hamadah ${ }^{1}$
}

ORCID IDs of the authors:

M.G.A.A. 0000-0002-3412-8825

A.O. $\quad 0000-0002-6381-6133$

M.A. 0000-0001-6691-6992

O.H. 0000-0002-2308-0547

M.A. 0000-0003-1263-5399

H.N. 0000-0002-4237-6837

1 Department of Oral Medicine, Faculty of Dentistry, Damascus University, Damascus, Syria.

${ }^{2}$ Department of Orthodontic and Maxillofacial Orthopedic, Faculty of Dentistry, Damascus University, Damascus, Syria.

${ }^{3}$ Department of Oral Histology and Pathology, Faculty of Dentistry, Damascus University, Damascus, Syria.

${ }^{4}$ Department of Forensic Medicine, Faculty of medicine, Damascus University, Damascus, Syria.

Received : 23.01.2020

Accepted : 06.05 .2020

How to Cite: Abofakher M. G. A, Owayda A, Al-assaf M, Hamadah O, Abdul-hak M, Nofal H. Mandibular Sexual Dimorphism Analysis in CBCT Scans in a Syrian Sample. Cumhuriyet Dent J 2020;23:2;124-128.

*Corresponding Author:

Department of Oral Histology and Pathology, Faculty of Dentistry, Damascus University, Damascus, Syria.

Phone: +96 $3991880364 \quad$ Email: dr.maher.assaf1990@gmail.com 


\section{INTRODUCTION}

Sex identification using human remains is considered to be an important concern in forensic anthropology practice. Sex identification considered to be very difficult especially when the remains are decomposed or just bones. ${ }^{1,2}$

Human pelvis bone is considered to be the most important bony standards that involve remarkable sexual dimorphism, with accuracy up to $95 \%$ followed by cranial and long bones with approximate $92 \%$ accuracy. All previous bones will be decomposed or lost due to the big size and fragility as postmortem changes. ${ }^{3}$ The mandibular bone is very important as one of the hardest, most durable of cranial bones and has more form variations according to sex. ${ }^{4}$

3D radiography, such as CBCT and CT scans, is used in bone measurements for many medical purposes. ${ }^{5,6}$ Many anatomical landmarks exhibit the different features between males and females. In general, the mandible size in males is bigger than in females, whereas mandibular gonial angle is more rounded in females compared with males. ${ }^{7}$ The maximum height and width of ramus increased in males more than in females due to differences in masticatory muscles efficacy between males and females. A systematic review ${ }^{7}$ has found that $87.5 \%$ of mandibular radiographic studies on adults, also $75 \%$ of studies on pre-identified dried mandibular bones of human remain showed significant differences between both sexes and referred to the lower jaw importance as an index in different races for sex determination. ${ }^{7}$

The forensic studies on Middle East populations are very few, although repeated armed conflicts in this area and the increased number of victims daily, there was a high need to find additional sex identifying indices for Syrian population-based on mandibular measurements. This study aimed to assess four mandibular indices for sex identification in the Syrian population including minimum breadth of the right ramus, the distance between coronoid process peak to gonion at a mandibular angle on the right side, right mandibular gonial angle, bigonial width.

\section{MATERIALS AND METHODS}

An approval was gained from the Ethics Committee at Damascus university to conduct the study (Approval ref: 283/2017).

This study is a retrospective cross-sectional study.

107 CBCT scans were randomly collected from the department of orthodontics and maxillofacial orthopedic at Damascus university. The inclusion criteria were patients Aged between 18-25 years of Syrian origin. CBCTs with the flowing cases were excluded: acquired or developmental deformation, severe asymmetry, old or new mandibular fracture, loss of two or more teeth and periodontitis. Finally, just 99 CBCT radiographs were included in the current study (56 females -43 males).

The CBCT images were taken using the same CBCT scanner (Planmeca ProMax 3D Mid; Planmeca Oy; Helsinki, Finland) with a voxel size of $0.3-0.4 \mathrm{~mm}$.

OnDemand3D program ${ }^{\mathrm{TM}}$ (Cypermed Inc., Seoul, Korea) was used to study CBCT images. As shown in (Figure 1) and the measurements were made on the $3 \mathrm{D}$ reconstructions, on the lateral view the following points were determined Gonion (Go: the most inferior posterior point on the mandibular angle), Gnathion ( $\mathrm{Gn}$ : the most lower anterior point on the chin). Condylon (Co: the most upper posterior point on the lateral face of condyle), Coronoin (Cor: the most upper posterior point on the coronoid process). After that these measures were taken: The right side Gonial angle (Co-Go-Gn), $\mathrm{Mr}-\mathrm{Br}$ (the minimum breadth of the right side ramus between anterior and posterior of ramus edges), Cor-Go (the distance between Coronoin and gonion points). On the axial view, the bigonial width (the distance between right and left gonion points) was measured as shown in (Figure 1). 


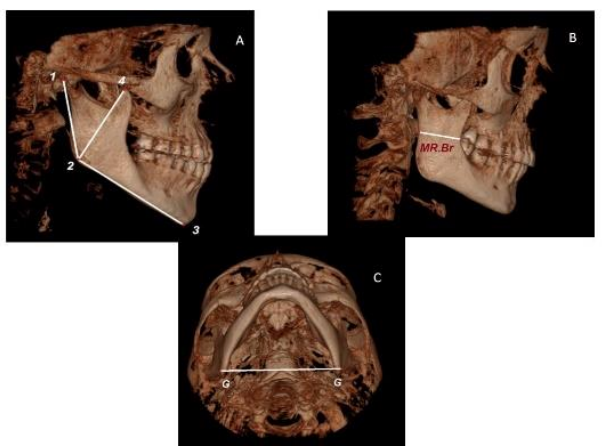

Figure 1: (a) measurement of the gonial angle 1-2-3 and the distance between Co-Go 2-4, (b) measurement of minimum ramus breadth and (c) measurement of the distance between right and left gonion

All measurements were carried out by two observers and on two occasions (the $2^{\text {nd }}$ after two weeks of the first occasion).

\section{Statistical Analysis}

Data analyzed using SPSS software (version 20; IBM, Armonk, New York). Data distribution was tested with the Kolmogorov-Smirnov test. The independent sample $\mathrm{t}$-test was employed to explore the differences in $\mathrm{Mr}-\mathrm{Br}$, Cor-Go, bigonial width and the gonial angle between males and females. Discriminant functional analysis was used to determine the accuracy of the aforementioned measures for sex identification purposes. The intraclass correlation coefficient ICC values for all variables were ranged from $94 \%$ to $99 \%$ and showed a high level of agreement and reliability for both interobserver and intraobserver measurements.

\section{RESULTS}

This study was carried out on 99 CBCT scans for individuals aged between 18 and 25 years (56 females, 43 males). Kolmogorov-Smirnov test showed that data was normally distributed. The independent sample T-test showed that all the indices were statistically significant as shown in (Table 2).

Table 1: Descriptive statistics of the Syrian sample including males and females.

\begin{tabular}{ccccccc}
\hline Variable & N & Minimum & Maximum & Range & Mean & SD \\
\hline MinRamBreadth & 99 & 21.60 & 35.50 & 13.90 & 28.65 & 2.92 \\
Gonial Angle & 99 & 103.30 & 149.50 & 46.20 & 129.60 & 7.22 \\
Co- Go & 95 & 41.20 & 70.10 & 28.90 & 56.07 & 6.40 \\
BiGonial width & 99 & 76.65 & 108.10 & 31.45 & 90.46 & 6.93 \\
\hline
\end{tabular}

MinRamBreadth: minimum ramus breadth.

Co-Go; cordonion-gonion distance

Table 2: T-test for comparison between males and females for all indices, * significant difference.

\begin{tabular}{|c|c|c|c|c|c|c|c|c|}
\hline Variabel & Sex & $\mathrm{N}$ & Mean & $\mathrm{SD}$ & P-value & Mean difference & \multicolumn{2}{|c|}{$\begin{array}{c}95 \% \text { confidence interval of } \\
\text { difference }\end{array}$} \\
\hline \multirow{2}{*}{ MinRamBreadth } & Male & 43 & 29.63 & 2.90 & \multirow{2}{*}{$0.003^{*}$} & \multirow{2}{*}{1.73} & \multirow{2}{*}{0.60} & \multirow{2}{*}{2.86} \\
\hline & Female & 56 & 27.89 & 2.73 & & & & \\
\hline Gonial Angle & Male & 43 & 127.11 & 7.87 & $0.002 *$ & -4.40 & -7.19 & -1.62 \\
\hline \multirow{2}{*}{ Co - Go } & $\begin{array}{c}\text { Female } \\
\text { Male }\end{array}$ & $\begin{array}{l}56 \\
43\end{array}$ & $\begin{array}{l}131.52 \\
58.61\end{array}$ & $\begin{array}{l}0.00 \\
6.78\end{array}$ & \multirow{2}{*}{$<0.001 *$} & \multirow[b]{2}{*}{4.63} & \multirow[b]{2}{*}{2.18} & \multirow[b]{2}{*}{7.09} \\
\hline & Female & 52 & 53.97 & 5.26 & & & & \\
\hline BiGonial width & $\begin{array}{l}\text { Male } \\
\text { Female }\end{array}$ & $\begin{array}{l}43 \\
56\end{array}$ & $\begin{array}{l}95.17 \\
86.84\end{array}$ & $\begin{array}{l}6.45 \\
4.81\end{array}$ & $<0.001 *$ & 8.32 & 6.08 & 10.57 \\
\hline
\end{tabular}

MinRamBreadth: minimum ramus breadth.

Co-Go: cordonion-gonion distance.

* significant difference

The most significant index between males and females was the bigonial distance (mean; 95.17 $\mathrm{mm}$ for males, $86.84 \mathrm{~mm}$ for females), followed by Gonial angle and Co-Go distance. Since all variables showed significant differences between males and females, all data subjected to discriminant functional analysis. the following function was derived:

$\mathrm{D}=-8.535+0.042 \mathrm{Mr}-\mathrm{Br}-0.053$ gonial Angle 0.01 Co-Go +0.162 bigonial width

If $\mathrm{D}$ score was less than zero, then this indicates female, and if it was above zero, this indicates male, with males and females centroids, 
are 0.864 and -0.715 respectively. On the other hand, specificity and sensitivity of the last function were $79 \%$ and $80 \%$ respectively and the diagnostic accuracy was $79.6 \%$.

\section{DISCUSSION}

Sex identification methodology of skeletal remains involves many ways which can differ between males and females. Many methods are based on the form description of the studied bones, which often influenced by subjective opinions and this decreases its accuracy, also reliability that varies among examiners. ${ }^{8}$ Therefore, the metric measurements of the skeletal features are considered to be more reliable for identification processes.

Several factors must be taken into consideration before determining the significance of a feature to be accepted as an index for sex identification. The morphological structure of this characteristic should reflect a sex-related form, and also must be able to resist decomposition for a long period. ${ }^{9}$

Al-Shamout et al. ${ }^{10}$ reported that many mandibular features change over time. The gonial angle of mandibular bone was one of the most affected features because of changes in the masticatory forces due to lack of effectiveness of mastoid muscles with aging, which directly affect the muscular activity causing remodeling of the lower jawbone. In contrast, De Oliveira et al. ${ }^{11}$ found that mandibular radiographic cephalometric indices were unable to predict sex under the age of 16 years. Therefore mandible (Lower jaw bone) was adopted in our study, and young ages were chosen for the sample, because this is useful in the case of unidentified corpses resulting from the armed conflict, especially in Syria, and because the bones of elderly people may change its morphology due to Muscular function or osteoporosis. ${ }^{10}$

The results of this study were similar to De Oliveira Gamba et al. ${ }^{12}$ results, Which was conducted on $160 \mathrm{CBCT}$ images of Brazilian society ages between 18 to 60 years. Our results were also agreed with those of Kharoshah et al. ${ }^{13}$ study which performed on Egyptian society, and their results showed that the possibility of determining the sex accurately reached $83.9 \%$ compared to $79.6 \%$ in the current study. The accuracy of mandible index in Syrians resulted in this study is about $79.6 \%$ which is close to $81.5 \%$ that resulted in Steyn \& Iscan study ${ }^{14}$ which considered a standard norm in South African Whites. ${ }^{8}$ Despite the results of this study are similar to many studies in the medical literature, ${ }^{15-}$ ${ }^{18}$ it disagrees with Ayoub et al. ${ }^{19}$ that conducted on the Lebanese society, which is ethnically similar to Syrian society. Ayoub et al. showed that Gonial angle did not have significant statistical differences between males and females. This difference might be due to using lateral cephalometric radiographs in the Lebanese study, that do not show an obvious difference between left and right sides and may cause a confusing when determining anterior and posterior borders of the ramus and the body of mandible compared with CBCT images which used in this study. The bigonial distance showed the highest difference between males and females, with an average distance in males was $95.2 \mathrm{~mm}$ and in females was $86.8 \mathrm{~mm}$. In contrast, this index showed higher accuracy in Indian society with an average distance of $103.5 \mathrm{~mm}$ for males and $78 \mathrm{~mm}$ for females, ${ }^{18}$ and it reached $101.17 \mathrm{~mm}$ in males and $93.97 \mathrm{~mm}$ in females in Greek society. ${ }^{20}$ These differences might be a result of ethnic differences between communities.

The small sample size in our study is considered to be as a limitation, therefore, an extended study must be carried out in future with different age groups and greater numbers of individuals.

\section{CONCLUSIONS}

The present study suggested that the sex of mandible in the Syrian population might be assessed by using metrical parameters as an additional tool to establish the identity of a person. However, the results of this study should be confirmed in a different sample of Syrian society.

\section{ACKNOWLEDGEMENT}

We want to declare that Damascus University has founded the entire project. 


\section{CONFLICTS OF INTEREST STATEMENT}

None.

\section{REFERENCES}

1. Burns KR. Forensic anthropology training manual: Routledge 2015:235.

2. Kanthem RK, Guttikonda VR, Yeluri S, Kumari G. Sex determination using maxillary sinus. J Forensic Dent Sci 2015;7:163-167.

3. Klepinger LL. Fundamentals of forensic anthropology: John Wiley \& Sons 2006:117-121.

4. Ramakrishnan K, Sharma S, Sreeja C, Pratima DB, Aesha I, Vijayabanu B. Sex determination in forensic odontology: A review. J Pharm Bioallied Sci 2015;7:S398-S402.

5. Akkaş I, Tozoğlu S, Çağlayan F, Özan F. The importance of CBCT imaging to determine the characteristics of a bone sequestrum in a case of chronic osteomyelitis. Cumhuriyet Dent J 2013;16:138-143.

6. Bayrak S, Sezgin OS, Kayıpmaz S, Çan G. The Effect of Slice Thickness on the Volume Estimations Performed by Using Cone Beam CT. Cumhuriyet Dent J 2018;21:167-172.

7. Hazari P, Hazari RS, Mishra SK, Agrawal S, Yadav M. Is there enough evidence so that mandible can be used as a tool for sex dimorphism? A systematic review. J Forensic Dent Sci 2016;8:174.

8. Indira AP, Markande A, David MP. Mandibular ramus: An indicator for sex determination-A digital radiographic study. J Forensic Dent Sci 2012;4:58-62.

9. Damera A, Mohanalakhsmi J, Yellarthi PK, Rezwana BM. Radiographic evaluation of mandibular ramus for gender estimation: Retrospective study. J Forensic Dent Sci 2016;8:74-78.

10. Al-Shamout R, Ammoush M, Alrbata R, AlHabahbah A. Age and gender differences in gonial angle, ramus height and bigonial width in dentate subjects. Pak Oral Dental J 2012;32:81-87.

11. de Oliveira FT, Soares MQS, Sarmento VA, Rubira CMF, Lauris JRP, Rubira-Bullen IRF. Mandibular ramus length as an indicator of chronological age and sex. Int J Legal Med 2015;129:195-201.
12. de Oliveira Gamba T, Alves MC, Haiter-Neto F. Mandibular sexual dimorphism analysis in CBCT scans. J Forensic Leg Med 2016;38:106-110.

13. Kharoshah MAA, Almadani O, Ghaleb SS, Zaki MK, Fattah YAA. Sexual dimorphism of the mandible in a modern Egyptian population. J Forensic Leg Med 2010;17:213-215.

14. Steyn M, İşcan MY. Sexual dimorphism in the crania and mandibles of South African whites. Forensic Sci Int 1998;98:9-16.

15. Dong H, Deng M, Wang W, Zhang J, Mu J, Zhu G. Sexual dimorphism of the mandible in a contemporary Chinese Han population. Forensic Sci Int 2015;255:915.

16. İlgüy D, İlgüy $M$, Ersan $\mathrm{N}$, Dölekoğlu $\mathrm{S}$, Fişekçioğlu E. Measurements of the foramen magnum and mandible in relation to sex using CBCT. J Forensic Sci 2014;59:601-605.

17. Saini V, Srivastava R, Rai RK, Shamal SN, Singh TB, Tripathi SK. Mandibular ramus: An indicator for sex in fragmentary mandible. J Forensic Sci 2011;56:s13-s16.

18. Vinay G, Mangala Gowri S, Anbalagan J. Sex determination of human mandible using metrical parameters. J Clin Diagn Res 2013;7:2671-2673.

19. Ayoub F, Rizk A, Yehya M, Cassia A, Chartouni S, Atiyeh F, et al. Sexual dimorphism of mandibular angle in a Lebanese sample. J Forensic Leg Med 2009;16:121-124.

20. Kranioti EF, García-Donas JG, Langstaff H. Sex estimation of the Greek mandible with the aid of discriminant function analysis and posterior probabilities. Rom J Leg Med. 2014;22:101-104. 